\title{
A Case Study on the Characteristics and Development of Minority Traditional Sports Curriculum Construction in Wenshan University*
}

\author{
Kaiwen $\mathrm{Li}$ \\ Physical Education School, Wenshan University \\ Wenshan, China 633099
}

\author{
Wu Liu** \\ Yunnan Vocational College of Mechanial \& Electrial \\ Technology \\ Kunming, China 650203 \\ ***Corresponding Author
}

\begin{abstract}
This paper makes a case study of the minority traditional physical curriculum in the major of physical education of Wenshan University, clarifies the experience and existing problems of the minority traditional physical education curriculum in the construction process, and according to the requirements and training objectives of the major, this paper puts forward that it's necessary to form the minority traditional sports curriculum with local characteristics based on the local minority traditional sports culture; curriculum design should be combined with national, professional and epochal nature; at the same time, the construction of minority traditional sports curriculum should give full play to regional advantages and make use of the advantages of other disciplines. In order to highlight the depth and breadth, it's wise to seek the intersection of curriculum setting, teaching and scientific research so that a featured development can be reached.
\end{abstract}

Keywords-minority traditional sports; curriculum characteristics; curriculum setting

\section{INTRODUCTION}

With the popularization of higher education in our country, the major of physical education has made rapid development in many sports colleges and universities and comprehensive normal colleges, mainly for the fast progress of professional scale, especially in many comprehensive colleges and universities, where the major of physical education relies on the preponderant discipline of the school to expand some new disciplines and interdisciplinary. There has been a pluralistic development in physical education courses. It is pointed out in the "National Undergraduate Course Program of Physical Education in Universities and Colleges" that it's a great significance of actively carrying out regional traditional physical education courses, further deepening the teaching reform of physical education in colleges and universities, improving the quality of education and teaching to train sports talents that meet the needs of quality education. It also more clearly pointed out the importance of regional traditional physical education curriculum in professional teaching.

Traditional sports of ethnic minorities is a unique way of

*Yunnan Provincial Department of Education planning project: 2014 Y477. fitness and recreation activities of ethnic minorities. More importantly, it reflects the cultural characteristics of ethnic minorities. As an important part of physical education in China the sports of ethnic minorities can not only be used as the main means of physical exercise, but also shape students' body forms, cultivate their good psychological quality and boost mental health [3]. Therefore, the incorporation of minority sports into the curriculum system of physical education both serves to enrich the curriculum content and grant more significance to the inheritance of national culture.

Wenshan University is located in the border area of the motherland, with a large number of ethnic minorities, so, its regional characteristics of ethnic minorities are more obvious. In 2009 , according to the professional development needs and regional characteristics, the College began to add ethnic minority sports courses with the concept of grasping the traditional advantages and highlighting national characteristics. In order to optimize the structure of minority traditional physical education curriculum and highlight the characteristics of physical education, hereafter the author will analyze the path and problems in the construction of minority traditional physical education curriculum.

\section{ETHNIC MINORITY TRADITIONAL SPORTS CURRICULUM SETTING}

\section{A. The Starting Point of Traditional Sports Curriculum for Ethnic Minorities}

Curriculum construction is a regular basic work in the teaching of colleges and universities. The quality of curriculum construction determines the quality of personnel training and strengthening curriculum construction is the basic way to improve teaching quality. Traditional minority sports curriculum in the border areas of primary and secondary schools has a good geographical basis, ethnic basis and local school-based curriculum development needs. According to the characteristics of school running and the needs of professional development, it is believed that the construction of minority traditional physical education curriculum can not only strengthen the quality of professional training, but also promote the comprehensive development of students. In the 
mean time, it is also conducive to the construction of schoolbased characteristic courses and the inheritance of minority culture.

\section{B. Guiding Ideology of Traditional Sports Curriculum for Ethnic Minorities}

Ethnic minority traditional sports curriculum design follows the principle of realizing the goal of cultivating physical education professionals, which is its starting point and foothold, highlighting the regional characteristics of the curriculum and the advantages of colleges, which is the running principle of the college.

\section{ThE SETTING OF TRADITIONAL SPORTS CURRICULUM FOR ETHNIC MINORITIES}

In the specialty curriculum, the minority traditional physical education should be the compulsory course. It should take the national traditional sports items and regulations, the national traditional sports health preservation as the supplement and extension of the traditional ethnic sports curriculum, that is, as an elective course. Through the study of minority traditional physical education curriculum, students can not only solve the basic problem of inheritance and succession of minority traditional sports skills, but also hold the main means of physical exercise, and gain good psychological quality. Meanwhile, the curriculum helps to guide students' creativity in the inheritance of national culture and assist in the construction of local culture.

TABLE I. PHYSICAL EdUCATION CURRICULUM FOR MiNORITy NATIONALITIES

\begin{tabular}{|c|c|c|c|c|c|c|c|}
\hline Category & Curriculum & & $\begin{array}{c}\text { Theoretical } \\
\text { Hours }\end{array}$ & Proportion & Skill Hours & Proportion & $\begin{array}{c}\text { Assessment } \\
\text { Method }\end{array}$ \\
\hline $\begin{array}{l}\text { Major } \\
\text { compulsory }\end{array}$ & Minority traditional sports & 4 & 12 & $16 \%$ & 60 & $84 \%$ & Examination \\
\hline \multirow[t]{3}{*}{$\begin{array}{l}\text { Major elective } \\
\text { courses }\end{array}$} & $\begin{array}{l}\text { National traditional sports programs and } \\
\text { regulations }\end{array}$ & 2 & 12 & $33 \%$ & 24 & $67 \%$ & Check \\
\hline & National traditional sports health preservation & 2 & 24 & $67 \%$ & 12 & $33 \%$ & Check \\
\hline & $\begin{array}{l}\text { Teaching practice of minority traditional } \\
\text { sports }\end{array}$ & 2 & 12 & $33 \%$ & 24 & $67 \%$ & Check \\
\hline
\end{tabular}

From "Table I", it can be seen that the traditional ethnic minority sports curriculum is set up by the combination of skills courses and theoretical courses, highlighting the characteristics of traditional ethnic sports. In the class time allocation, it focuses on skills, stressing the characteristics of sports profession, more flexible in examination methods. Each of the above-mentioned courses has its own functions. Each course is interrelated and complementary to each other, but there are differences between them. So the differences between them and their interrelationship deduce the systematic functions, that is, traditional sports of ethnic minorities have the functions of sports skills, sports culture and sports education in professional training.

\section{A. Construction of Teacher Teams for Minority Traditional Sports Courses}

A stable team of teachers is the main link of the curriculum construction.According to the management regulations on the curriculum construction of the physical education college, the lecturers of traditional sports of ethnic minorities must own lecturership or higher professional ranks and titles or master's degree or higher degrees.Secondly, and the new teachers need pre-job training. They can undertake the courses only after receiving the "passing, helping and carrying" training. In 2008 and 2010, the physical education college introduced two curriculum teachers of minority traditional sports majors.At the same time, the college encourages and supports professors and associate professors with senior professional titles to actively engage in the development and teaching of minority sports courses, and takes effective measures to implement the supporting according to the needs of the courses.

\section{B. Construction of Minority Traditional Sports Classes}

According to the forms and characteristics of traditional sports of ethnic minorities,traditional sports of ethnic minorities are classified into: entertainment sports, fitness exercises and religious sports.According to the requirements for class construction of the physical education college, students are placed at the core of the courses.The teachers combine the traditional sports skills of ethnic minorities with the national culture and properly apply various advanced teaching methods to effectively mobilize the students' enthusiasm for learning and promote the continuous improving of students' learning abilities.For example, in the minority traditional sports courses, there is a course of blowing gun. The blowing of guns originated from the production and living practices of fowling of the Miao people.In the course, the teachers need to improve the teaching equipment, transform the original "bullet" of fowling,and choose the appropriate teaching methods to meet the course requirements.

\section{Construction of Practice Bases and Sports Competitions for Minority Traditional Sports Courses}

In 2010, the School of Physical Education got the training points for the minority traditional sports of ancient game of kicking a ball and high foot race speed from the Prefecture Ethnic Affairs Commission and the Sports Bureau.At the same time, the college carried out sports such as sneakers, bowing, blowing guns, and spinning tops, and established minority traditional sports course practice bases. Under the guarantee of funds, the School of Physical Education won 9 gold medals, 14 silver medals and 12 bronze medals in the traditional sports items of ethnic minorities at the 8th National Games in 
Wenshan Prefecture. The total score of the group ranked third in the prefecture and the performance project won the third prize. The school won 3 gold medals, 2 silver medals and 4 bronze medals at the 10th National Minority Games in Yunnan Province. From the point of view of the award-winning items, the main items are blowing guns, ancient kicking balls and board shoes, and the award-winning scope is narrow.

\section{Construction of Scientific Research for Minority Traditional Sports}

With the advent of the knowledge economy, the development of sports science research will accelerate from two aspects: vertical and horizontal. It is difficult to solve the major problems in traditional sports of ethnic minorities in a single traditional sports research of ethnic minorities. Diversified research is an inevitable trend.Utilizing its own human resources and team advantages, and taking the construction of characteristic disciplines as the starting point,the School of Physical Education firstly introduces the professional talents of minority traditional sports, and secondly trains them, finally forms the basis for the development of minority traditional sports research taking the external communication and discipline team building as the basic construction approach, social practice and field investigation as the basic bridge, results as the supporting basis, and classroom teaching as the core.

TABLE II.

LIST OF MiNORITY TRADITIONAL SPORTS SCIENTIFIC RESEARCH CONSTRUCTION

\begin{tabular}{|c|c|c|c|c|c|c|}
\hline Category & Curriculum & $\begin{array}{c}\text { Theoretical } \\
\text { Hours }\end{array}$ & Proportion & Skill Hours & Proportion & $\begin{array}{c}\text { Assessment } \\
\text { Method }\end{array}$ \\
\hline $\begin{array}{l}\text { Major } \\
\text { compulsory }\end{array}$ & Minority traditional sports & 12 & $16 \%$ & 60 & $84 \%$ & Examination \\
\hline \multirow[t]{3}{*}{$\begin{array}{l}\text { Major elective } \\
\text { courses }\end{array}$} & $\begin{array}{l}\text { National traditional sports programs and } \\
\text { regulations }\end{array}$ & 12 & $33 \%$ & 24 & $67 \%$ & Check \\
\hline & National traditional sports health preservation & 24 & $67 \%$ & 12 & $33 \%$ & Check \\
\hline & $\begin{array}{l}\text { Teaching practice of minority traditional } \\
\text { sports }\end{array}$ & 12 & $33 \%$ & 24 & $67 \%$ & Check \\
\hline
\end{tabular}

In the past three years, the scientific research level of minority traditional sports courses has risen rapidly.Over the past three years, more than 60 papers related to traditional sports of ethnic minorities have been published. The teacher team of the college is the editor-in-chief of one textbook.Through the efforts of the research team, the college has obtained 2 planning projects of Yunnan Philosophy and Social Science, 3 planning projects of Yunnan Provincial Education Department, 9 projects of Yunnan Provincial Education Department Guiding Project and Wenshan University Research Fund Project,with 10 papers published on the core publications.From the main contents of the topics and the research of the theses, the research is focused on the following aspects, firstly, the study of traditional sports culture of ethnic minorities,followed by the study of traditional sports of ethnic minorities into classroom teaching, and then the study of teaching practice of traditional sports of ethnic minorities.

\section{PROBLEMS ENCOUNTERED IN THE PRACTICE OF BUILDING MiNORITY TRADITIONAL SPORTS COURSES}

\section{A. Problems Existing in the Current Physical Education Major Curriculum System}

From the perspective of the physical education major curriculum system, it includes general education courses, teacher education courses, professional courses, independent practice courses. These courses do not reflect the characteristics of Wenshan University. That is, they don't reflect the regional, national, and open characteristics. The physical education major courses mainly transplant the curriculum system of similar majors.In fact, the physical education major has scraped together the general education courses, teacher education courses, professional courses and independent practice courses. It is practical for cultivating students' professional ability. From a macroscopic point of view, the deep-seated problem of the curriculum is the lack of regional and national professional characteristics.The curriculum system of physical education major is somewhat similar to that of other similar institutions, and it lacks pertinence for the training of physical education major students.

\section{B. The Objectives of a Few Traditional Physical Education Curriculums Separate from the Objectives of Physical Education Training, Which Is Not Conducive to Achieving the Characteristic Orientation of Wenshan University}

The expression of the objectives of a few current traditional sports curriculums does not correspond to the training objectives of the sports major. The training objectives of sports major are: to cultivate professional sports education talents who have good scientific and cultural literacy, master the basic theories, basic knowledge and basic skills of sports, and can engage in university physical education, university sports science research, university sports management, and social sports guidance [6]. The curriculum objectives of traditional minority national sports enable students to understand the general situation of traditional minority national sports, formation and development of traditional minority national sports and relationship between traditional minority national sports and traditional Chinese culture, and master the basic theory and method of traditional minority national sports. The traditional minority national sport is a basic point to realize the target structure of physical education major, and serves the overall goal. In this respect, there are obvious shortcomings in the traditional minority national sports, which fails to reflect the particularity of professional physical education talents. From the perspective of realizing Wenshan 
University's school-running characteristics, it doesn't reflect the special status and function of the curriculum in carrying forward local national culture. Therefore, it still needs to be further explored, practiced and improved.

\section{The Single Curriculum Setting of Traditional Physical} Education for Regional Minority Cannot Highlight the Interdisciplinary Nature, Which Is Not Conducive to the Development and Cultural Inheritance of Minority Sports

From the perspective of curriculum setting, traditional minority national sports is a compulsory curriculum for the students, and national traditional sports events and regulations and national traditional sports health studies are optional courses for the students. Traditional minority national sports is an integral part of sports, as well as an important part of national culture. Therefore, traditional minority national sports not only reflects the nature of sports skills, but also includes knowledge of ethnic culture, ethnic anthropology, and ethnic sociology. From the in-depth perspective of curriculum development, due to the lack of cross-disciplinary support, the development of traditional national sports only has its from, but lacks its connotation, therefore, it cannot be sustained.

\section{The Development of Traditional Minority National Sports Lacks the Time Characteristics}

Along with the development of communication means and easy information exchange, traditional national sports are known to more students and the general public. The nationality, regionality, entertainment, unique cultural and artistic aesthetic values and humanistic connotations of traditional national sports are not available for the era sports[7]. However, we moderately publicize the traditional minority national sports by using modern media, and appropriately innovate and transform it by means of modern sports, so that the traditional minority national sports will play a greater role in the development of the profession and region, and social harmony and progress.

\section{DEVELOPMENT PATH OF TRADITIONAL MINORITY NATIONAL SPORTS CURRICULUM}

\section{A. Focusing on Wenshan University's Characteristics of Regionality, Nationality and Openness, and Enhancing the Features of Traditional Minority National Sports Curriculum}

Based on the regional, national and open characteristics of Wenshan University, we will further explore and sort out the traditional national sports and culture in Wenshan Prefecture, and deeply study the generation and development mechanism of traditional national sports and culture and its education function and social function. Then, we will conduct a targeted analysis according to the traditional minority national sports events and its cultural characteristics. On this basis, we will introduce the traditional minority national sports into the teaching system and put it into practice. This is not only conducive to professional development and cultural inheritance, but also beneficial to the improvement of schoolrunning characteristics.
B. Giving Full Play to the Advantages of Local Universities, Relying on the Advantages of Other Disciplines of the University, Seeking Common Ground in Training Mode, Academic Research, Teaching Resources and Other Aspects, and Making Use of Resources for Development

We should not blindly imitate other universities to set the subjects. It is necessary to establish a mutually beneficial "common domain" in disciplinary cluster of the university and among different subjects to develop traditional national sports curriculum[8]. The traditional minority national sports is not just the acquisition of sports skills, and the learners should also shoulder the heavy responsibility of inheriting and carrying forward the national culture. Only by comprehending the profound cultural background of traditional minority national sports from different disciplines can we lay a solid theoretical foundation for the study and communication of traditional minority national sports. For example, traditional minority national sports include the knowledge of sports science, ethnology, anthropology, and sociology. As a comprehensive university, Wenshan University contains different kinds of disciplines. To this end, the development of traditional minority national sports should not only take advantage of the local university of Wenshan University, but also seek cooperation in training mode and academic research relying on the advantages of ethnology, sociology and other disciplines of Wenshan University. Furthermore, we can share curriculum resources featured by traditional minority national sports, and enhance its school-running characteristics.

\section{Improving the Teaching Mechanism of Traditional Minority National Sports}

As viewed from the current situation, the traditional sports teaching of minorities stays in an early stage, and its teaching has not formed a normative system, which has seriously restricted the scientific development of traditional minority national sports. Therefore, it is particularly important to improve the teaching mechanism of traditional minority national sports. First of all, we must set reasonable teaching objectives, and strengthen the intensity and depth of traditional minority national sports curriculum in the professional curriculum. Secondly, we must analyze the rationality and feasibility of traditional minority national sports teaching to provide basic guarantee for classroom teaching. Thirdly, we must improve the evaluation mechanism of traditional minority national sports.

\section{Strengthening the Construction of Academic Teams and Enhancing the Connotation and Value of Traditional Sports of Ethnic Minorities}

Scientific research is an important function and modern universities are paying more and more attention to it. With the development of higher education, the research of sports disciplines has beening showing the cross and comprehensive characteristics day by day, which needs the theoretical support of various disciplines such as social sciences and natural sciences. 


\section{E. Strengthening Exchanges Among Brother Universities}

We should strengthen the development of teaching exchange activities among brother universities, explore effective ways for minority traditional sports in the field of education and teaching, especially in the teaching reform of teaching mechanisms and cultural heritage of ethnic minorities, and strive for a wider range of research samples to improve the validity and reliability of the research and to gradually expand the radiation range of traditional sports skills and cultural heritage of ethnic minorities.

\section{CONCLUSION}

Extremely rich in sports essence, traditional sports of ethnic minorities is highly concentrated in national culture and is a link for transmission of national culture. The education of traditional sports of ethnic minorities is responsible for cultivating special talents engaged in traditional sports education and sports research for ethnic minorities. This is just the foundation and hope for the traditional sports of ethnic minorities to go to the world. Physical Education School of Wenshan University has carried out a useful attempt to incorporate traditional sports of minority into the sports system of this school. However, the course construction of traditional sports of minority at Wenshan University is still in its infancy. It is recommended to follow the principle of practice, study, optimization, and improvment.

\section{REFERENCES}

[1] Zhao Jiyang, Zou Xiaoer et al. Survey of Current Curriculum Programs of Physical Education Major in Local Universities[J]. Journal of Jishou University(Natural Science Edition), 2008(1):86-89.

[2] Yang Weilin. Research on Establishment and Practice of Traditional Physical Education Teaching Mechanisms of Minority Nationalities in Colleges and Universities in Xinjiang[J]. Kickboxing - Wushu Science, 2014(1): 98-100.

[3] Tan Yingying. The current situation and countermeasures of the development of traditional sports of ethnic minorities in colleges and universities in Guizhou Province [D]. Master's thesis of Guangzhou Sport University, 2014.

[4] Jin Wei, Fu Ying. Discussion on the Reform of Undergraduate Curriculum Setting for Teaching Chinese as a Foreign Language[J]. Journal of Liaoning Normal University (Social Science Edition), 2011(6): 79-81.

[5] Wang Ping. On the Construction of Local Colleges and Universities- Taking Yangtze University as an Example[J]. Culture and Education Materials, 2014(7): 156-157.

[6] Hu Zhechun. Investigation and countermeasures on the status quo of Wushu courses in colleges and universities of physical education in Anhui Province [D]. Master's thesis of East China Normal University, 2009.

[7] Xiong Shengyao. The Development Process and Future Trend of the Traditional Sports of Chinese Minorities from the Perspective of Olympic Development[J]. Journal of Shaoyang University: Natural Science Edition, 2010(1): 70-73.

[8] Wu Xin. Research on the Characteristics Development of Physical Education Major Curriculum Construction in Overseas Chinese Schools --- A Case Study of the Curriculum Construction of Physical Education Major in Jinan University[J]. Journal of Beijing Sport University, 2011(9): 101-106 